University of Nebraska - Lincoln

DigitalCommons@University of Nebraska - Lincoln

Faculty Publications from the Department of Electrical \& Computer Engineering, Department Electrical and Computer Engineering

7-1969

\title{
A Noise Figure Lower Bound and a Frequency Converter
}

Grant Myers

University of Nebraska-Lincoln

Follow this and additional works at: https://digitalcommons.unl.edu/electricalengineeringfacpub

Part of the Electrical and Computer Engineering Commons

Myers, Grant, "A Noise Figure Lower Bound and a Frequency Converter" (1969). Faculty Publications from the Department of Electrical and Computer Engineering. 101.

https://digitalcommons.unl.edu/electricalengineeringfacpub/101

This Article is brought to you for free and open access by the Electrical \& Computer Engineering, Department of at DigitalCommons@University of Nebraska - Lincoln. It has been accepted for inclusion in Faculty Publications from the Department of Electrical and Computer Engineering by an authorized administrator of DigitalCommons@University of Nebraska - Lincoln. 


\title{
A NOISE FIGURE LOWER BOUND AND A FREQUENCY CONVERTER
}

\author{
Grant G. Myers \\ Department of Electrical Engineering \\ The University of Nebraska \\ Lincoln, Nebraska 68508
}

\begin{abstract}
This article establishes a lower bound for the noise figure of two networks in cascade. This is illustrated by means of a passive low-level frequency converter which utilizes a back diode as a nonlinear conductance. Other investigators have analyzed the properties of low-level frequency converters. However, the greatest lower bound of a combination of the converter and intermediate frequency amplifier system was not considered previously and is the subject of this paper. Knowledge of this lower bound has practical significance because if a measured value of noise figure is less than this lower bound, it follows that the measurement is in error.

For illustrative purposes a lower bound is established on one of the highest quality systems available, employing a special General Electric diode as a frequency converter for the first network, and a 60 $\mathrm{MHz}$ IF amplifier for the second network. This resulted in a noise figure lower bound of $3.86 \mathrm{db}$ for the overall system.

This paper shows how this lower bound was obtained. Also the controversial right angle diode characteristic is found to be undesirable from an impedance viewpoint.

\section{INTRODUCTION}

Lo $\{1\}$ and Pucel $\{3\}$ have investigated the properties of low-level frequency converters. However, the greatest lower bound on the noise figure of two networks in cascade was not considered and is the subject of this paper.* To practically illustrate this concept, a combination of a frequency converter as the first network and an intermediate frequency amplifier as

\footnotetext{
* This investigation was made possible through the facilities of the Collins Radio Company, Cedar Rapids, Iowa. Presented to Ninth Midwest Symposium on Circuit Theory, Oklahoma State University, Stillwater, Oklahoma, May, 1966.
}

the second network is investigated. The lower bound has practical significance because if a measured value of noise figure is less than this lower bound, it follows that the measurement is in error.

The frequency converter nonlinear conductance was a special General Electric diode SBD-524. A 60 $\mathrm{MHz}$ IF amplifier with a noise figure of $1.15 \mathrm{db}$ served as the second network. This combination was one of the highest quality systems available and resulted in a lower bound of $3.86 \mathrm{db}$ for the over-all system. This paper provides an illustration of how this value was obtained. Also, an analysis of the controversial right angle diode characteristic is presented.

\section{NOISELESS MIXER ANAYLSIS}

The purpose of this section is to discuss the theory of frequency conversion for the practical case of a small signal. A major portion of this theory has been firmly established by Herold and Malter $\{2\}$ and is partially included to provide a basis for obtaining a lower bound for noise figure.

Figure 1 is a diagram of a mixer, including voltages, which may be expressed as follows:

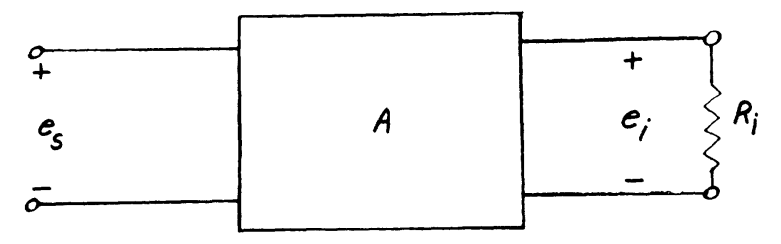

Figure 1 


$$
\begin{aligned}
& \mathrm{e}_{\mathrm{s}}=\mathrm{E}_{\mathrm{s}} \sin \omega_{\mathrm{s}} \mathrm{t} \\
& \mathrm{e}_{\mathrm{i}}=\mathrm{E}_{\mathrm{i}} \sin \left(\omega_{\mathrm{i}} \mathrm{t}+\phi\right) \\
& \left|\begin{array}{l}
\mathrm{E}_{\mathrm{i}} \\
- \\
\mathrm{E}_{\mathrm{s}}
\end{array}\right|=\mathrm{A} \\
& \text { where } \omega_{\mathrm{i}} \neq \mathrm{n} \omega_{\mathrm{s}} \\
& \mathrm{n}=1,2,3, \ldots \\
& \neq \frac{1}{n_{n}} \omega_{\mathrm{s}}
\end{aligned}
$$

Equation (4) eliminates the possibility of using a frequency multiplier or divider.

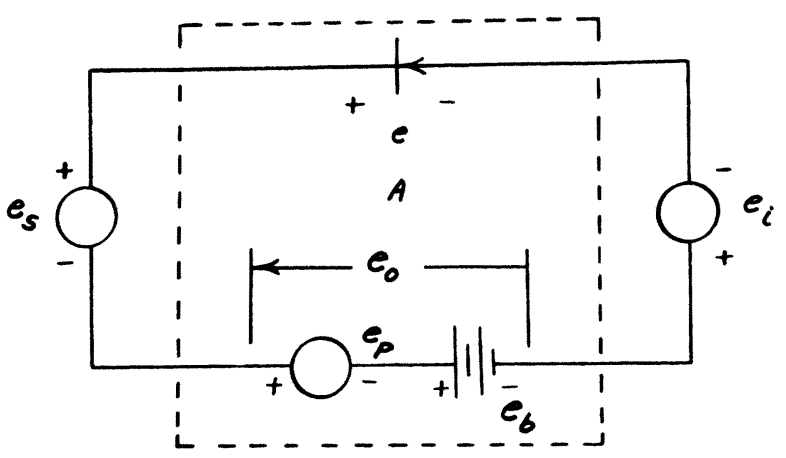

Figure 2

In consideration of the circuit of Figure 2, Pucel \{3\} specifies a more complex circuit utilizing three "ideal filters" as shown in Figure 3. However, the equations are written as though the circuit of Figure 2 were being considered.

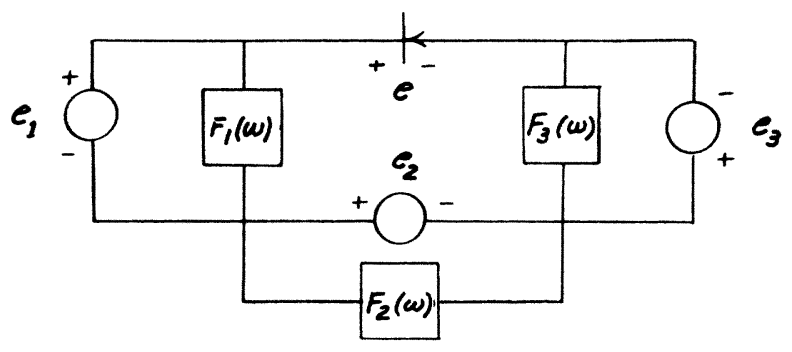

Figure 3

In practice the filters $F_{1}, F_{2}$, and $F_{3}$ are realized by means of tuned circuits and voltage exists only by virtue of the reactance at frequencies greater than the fundamental frequency, because if this reactance is eliminated, the voltage across the diode is zero.

It is possible to show that the circuit of Figure 2 may be simplified to that of Figure 4 for small signal operation where $I_{s}$ and $I_{i}$ are the signal current and IF current respectively, and $\mathrm{E}_{\mathrm{s}}$ and $\mathrm{E}_{\mathrm{i}}$ are the signal voltage and the IF voltage, respectively. The con-

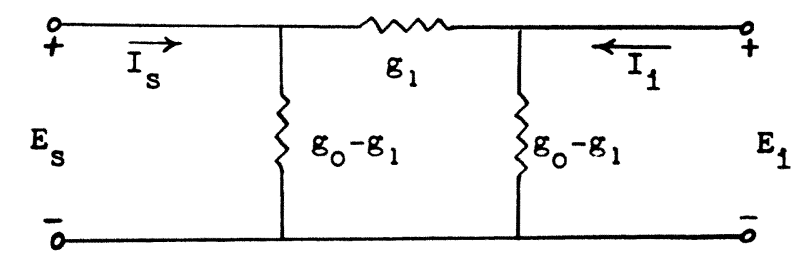

Figure 4

ductances $g_{0}$ and $g_{1}$ are related to the Fourier coefficients of the time varying diode conductance as follows:

$$
g(t)=g_{o}+2 g_{1} \cos \omega_{p} t+\ldots
$$

Thus, in matrix form the network equations are

$$
\left[\begin{array}{c}
I_{s} \\
I_{i}
\end{array}\right]=\left[\begin{array}{rr}
g_{o} & -g_{1} \\
-g_{1} & g_{0}
\end{array}\right]\left[\begin{array}{l}
E_{i} \\
E_{s}
\end{array}\right]
$$

The only precaution which must be applied to the $\pi$ circuit is that the output frequency and input frequency are not equal. However, with this exception, the $\pi$ circuit reveals all of the analytical characteristics of the mixer, such as characteristic impedance, gain, input circuit loss, etc.

The characteristic impedance is

$$
g_{x}=\sqrt{g_{0}^{2}-g_{1}^{2}}
$$

If the network is terminated in $\mathrm{g}_{x}$, the transfer function is

$$
\frac{E_{i}}{E_{s}}=\frac{g_{1} / g_{0}}{1+\sqrt{1-\left(\frac{g_{1}}{g_{0}}\right)^{2}}}
$$

Thus if $\frac{E_{i}}{E_{s}}=1$, then $\frac{g_{1}}{g_{o}}=1$. However, a gain of unity may not be realized in practice, because $\mathrm{g}_{\mathrm{x}}^{2}=\mathrm{g}^{2}-\mathrm{g}^{2}=0$. 
Since this paper is limited to passive mixers, it is necessary to consider only the case where $\left|g_{1}\right|<g_{0} \cdot\{3\}$ From equation (6):

$$
\frac{g_{o}}{g_{x}}=\sqrt{\frac{1}{1-\left(\frac{g_{1}}{g_{0}}\right)^{2}}}
$$

If the gain is unity, then $\frac{g_{1}}{g_{o}}=1$

where $g_{o}=\frac{1}{2 \pi} \int_{o}^{2 \pi} g\left(\omega_{p} t\right) d\left(\omega_{p} t\right)$

and $g_{1}=\frac{1}{2 \pi} \int_{0}^{2 \pi} g\left(\omega_{p} t\right) \cos \left(\omega_{p} t\right) d\left(\omega_{p} t\right)$

If $g\left(\omega_{\mathrm{p}} \mathrm{t}\right)=\mathrm{U}_{\mathrm{o}}(\mathrm{t}-\mathrm{n} 2 \pi), \mathrm{n}=0,1,2, \ldots$

where $U_{o}(t)$ is a unit impulse distribution , then $g_{0}=g_{1}$.

This conductance impulse could be approximated by a switch which is closed for a very short time once per cycle. However, since $g_{x}$ is zero, it may be concluded that in practice the gain of such a mixer which approximates this condition is considerably less than unity due to the impedance matching problem. It follows from (10) that the angle of conduction must be very small for the gain to be high.

Consider an "ideal diode" which has the characteristic shown in Figure 5. It follows that the angle of conduction is dependent on only the pump and is

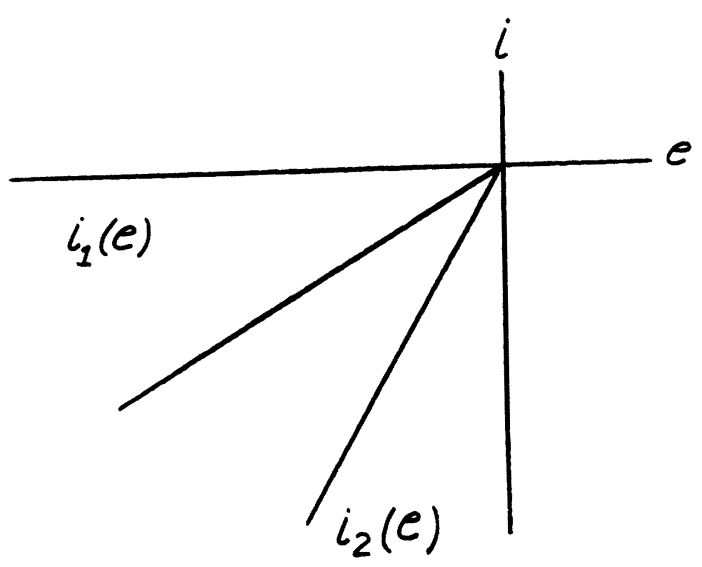

Figure 5

independent of the slope of the characteristic in the third quadrant. Thus, $i_{1}(e)$ and $i_{2}(e)$ per Figure 5 must result in the same gain. Also, if the pump bias is small, it follows that the gain is low because the conductance angle of $\pi$ radians is quite large. This conclusion is indeed correct as shown by the following analysis of gain versus $e_{b} / E_{p}$.

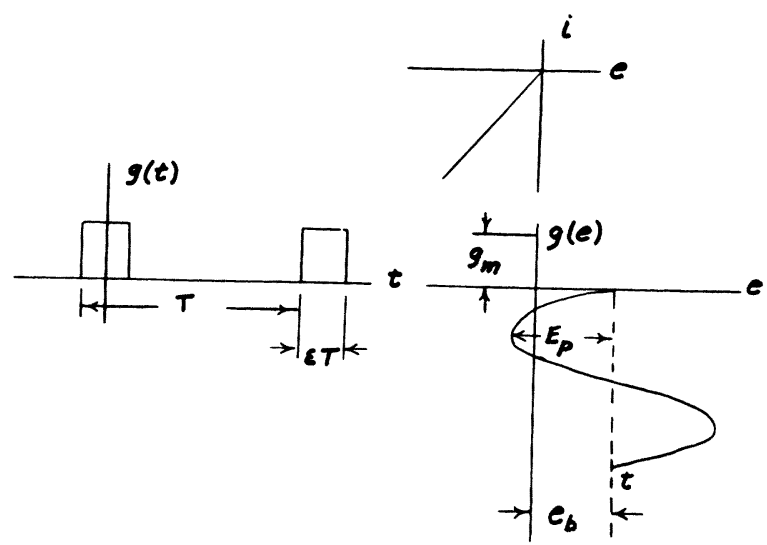

Figure 6

The Fourier expansion of $\mathrm{g}(\mathrm{t})$ (Figure 6) gives

$$
\begin{aligned}
& \mathrm{g}_{0}=\mathrm{g}_{\mathrm{m}} \varepsilon \\
& \mathrm{g}_{1}=\frac{\mathrm{g}_{\mathrm{m}}}{\pi} \sin (\pi \varepsilon)
\end{aligned}
$$

where $\varepsilon$ is the fraction of the time that current flows. Equations (11) and (12) give

$$
\frac{\mathrm{g}_{1}}{\mathrm{~g}_{0}}=\frac{\sin \pi \varepsilon}{\pi \varepsilon}
$$

From Figure 6

$$
\pi \varepsilon=\cos ^{-1} \frac{\mathrm{e}_{\mathrm{b}}}{\mathrm{E}_{\mathrm{p}}}
$$

Equations (13) and (14) give

$$
\frac{g_{1}}{g_{0}}=\frac{\left(E_{p}^{2}-e_{b}^{2}\right)^{1 / 2}}{E_{p} \cos ^{-1}\left(\frac{e_{b}}{E_{p}}\right)}
$$

Thus, the gain is independent of $g_{m}$.

$$
\text { If } \begin{aligned}
e_{b}=0 \text { (zero bias) then } \frac{g_{1}}{g_{o}} & =\frac{2}{\pi} \text { and the gain is } \\
20 \log _{10}\left(\frac{E_{1}}{E_{s}}\right) & =-8.88 \mathrm{db} .
\end{aligned}
$$

This would result in a poor over-all noise figure for a mixer IF system due to attenuation in the mixer when operating at the zero bias point.

If $\mathrm{g}_{\mathrm{m}}$ is permitted to become arbitrarily large, then the power dissipated in the diode might appear to become arbitrarily small since in the limit the VI product appears to be zero. This controversial concept is incorrect, however, because the attenuation is independent of $g_{m}$ and is constant. Thus, the difference between the power output and and the power input is dissipated in the diode and this difference remains constant as the "right angle characteristic" is approached if the power input, $e_{b}$ and $E_{p}$ are constant. 


\section{PRACTICAL RESULTS AND THE NOISE FIGURE LOWER BOUND}

The back diode characteristic (Figure 7) is somewhat similar to the characteristic of the ideal diode. From the preceding analysis it follows that if the abso-

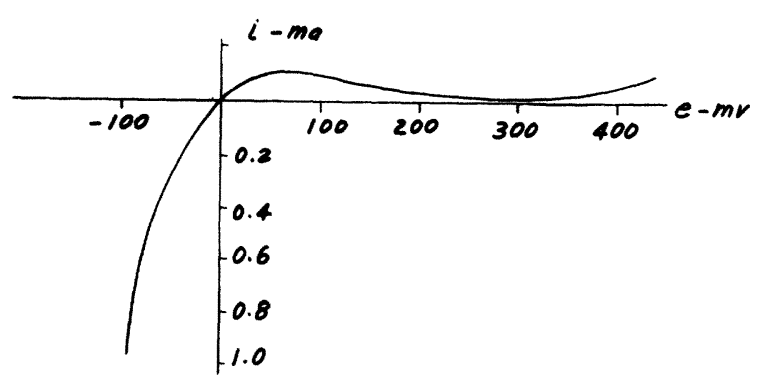

Figure 7

lute value of the negative conductance in the first quadrant is small enough, then the slope of the characteristic in the third quadrant determines the characteristic impedance and has an almost insignificant effect on the gain. However, this reasoning must be utilized with caution since the conductance is not constant.

For illustrative purposes Figure 8 is an example of the periodic conductance $\mathrm{g}(\mathrm{t})$ of a back diode which was tested.

Experimental results indicate that negative or positive values of bias cause the over-all noise figure to increase with respect to that at zero bias.

This occurs for negative bias because

1. A dc component results in more diode noise.

2. The gain of the mixer is lower due to the larger angle of conduction.

Also, this occurs for positive bias because apparently the increase in gain is more than compensated for by the increase in noise.

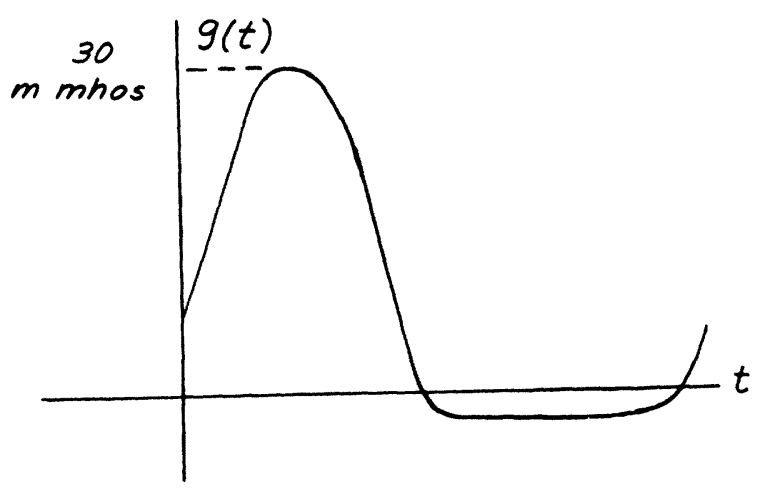

Figure 8
Lo $\{1\}$ reports that theoretically it is possible to obtain an over-all noise figure $F_{t}$ of $3.0 \mathrm{db}$ with a GE 4 JF2-BD-7 at $300 \mathrm{mv}$ bias and $200 \mathrm{mv}$ peak pump amplitude assuming that the IF noise figure is $1.3(1.14 \mathrm{db})$.

A mixer circuit was designed by the author and the results indicate that adding bias, especially a large amount such as $300 \mathrm{mv}$, resulted in an over-all noise figure of over $10 \mathrm{db}$ for converting from $220 \mathrm{MHz}$ to 60 $\mathrm{MHz}$ with the pump at $280 \mathrm{MHz}$ and an IF noise figure of $1.15 \mathrm{db}$. Only by decreasing the bias to zero could the amplitude of the pump be adjusted to obtain an over-all minimum noise figure of $7 \mathrm{db}$ using the BD-7 back diode. Using a special diode recommended by General Electric, the SBD-524, resulted in an overall noise figure of $6 \mathrm{db}$ under similar conditions. General Electric indicates that the best over-all noise figure which may be obtained by this special diode is 7 to 8 $\mathrm{db}$ for converting from $220 \mathrm{MHz}$ to $60 \mathrm{MHz}$.

If it is assumed that the IF noise figure is $1.15 \mathrm{db}$ and that the diode of Figure 8 is used, then a numerical analysis based on a noiseless mixer and the Friis formula indicates that the above result is indeed possible. Also, this analysis shows that an over-all noise figure of $3.86 \mathrm{db}$ or less is impossible to realize, which establishes the lower bound for noise figure.

The maximum mixer gain $\mathrm{E}_{\mathrm{i}} / \mathrm{E}_{\mathrm{s}}$ using zero bias and a peak pump voltage of $100 \mathrm{mv}$ is 0.459 . This value of gain was obtained by applying numerical integration to obtain the Fourier coefficients and applying equation (7). This is referred to as maximum mixer gain because this corresponds to the maximum pump voltage which may be applied without overdriving the diode and any value of pump voltage less than $100 \mathrm{mv}$ results in less gain, since pump voltage and gain are proportional to a first approximation. This effect of pump voltage on mixer gain shows that the SBD-524 back diode characteristic is significantly different from that of the "ideal diode" since the gain of the "ideal diode" is independent of the pump amplitude provided the bias is zero.

The power gain is $\left(\mathrm{E}_{\mathrm{i}} / \mathrm{E}_{\mathrm{s}}\right)^{2}=0.21$ for equal output and input impedance. In practice this may not be the case. However, this results in the measured value of noise figure being greater than the lower bound which is sought here.

A further restriction on the lower bound of the over-all noise figure is the noise figure of the IF amplifier. The lowest IF noise figure observed by the author is $1.15 \mathrm{db}$ or a ratio of 1.3 .

From the Friis formula,

$$
\begin{aligned}
& F_{T}=F_{1}+\frac{F_{2}-1}{A} \text { where } \\
& F_{T}=\text { total noise figure }
\end{aligned}
$$




$$
\begin{aligned}
& \mathrm{F}_{1}=\text { noise figure of the mixer }=1 \text { (ideal) } \\
& \mathrm{F}_{2}=\text { noise figure of the } \mathrm{IF} \text { amp }=1.3 \\
& \mathrm{~A}=\text { power gain of the mixer }=(0.458)^{2}=0.21
\end{aligned}
$$

Thus $\mathrm{F}_{\mathrm{T}}=1+\frac{1.3-1}{.21}=2.43$

and the lower bound is

$$
\mathrm{F}_{\mathrm{T}}=10 \log _{10} 2.43=3.86 \mathrm{db}
$$

The reasons for obtaining $6 \mathrm{db}$ rather than $3.86 \mathrm{db}$ in practice are as follows:

1. The noise figure of the mixer is greater than 1 (0db).

2. The power gain of the mixer is less than 0.21 $(-6.78 \mathrm{db})$ due to input and output circuit losses. (Also, there is experimental evidence that the best noise figure is obtained by a mismatch of impedance with respect to the output of the mixer and the input of the IF amplifier. Thus, $A$ is decreased so that $F_{2}$ may be decreased toward 1.3).

From Figure 6 the $6.78 \mathrm{db}$ loss is $2.1 \mathrm{db}$ less than that corresponding to the zero bias point of the "ideal diode." This is caused by two factors.

1. The SBD-524 has a negative resistance region.

2. The angle of "high conductance" is smaller on the SBD-524.

The contribution due to the negative resistance is only $0.1 \mathrm{db}$ and is therefore practically insignificant. This was established by removing the negative portion of the conductance curve and repeating the analysis.

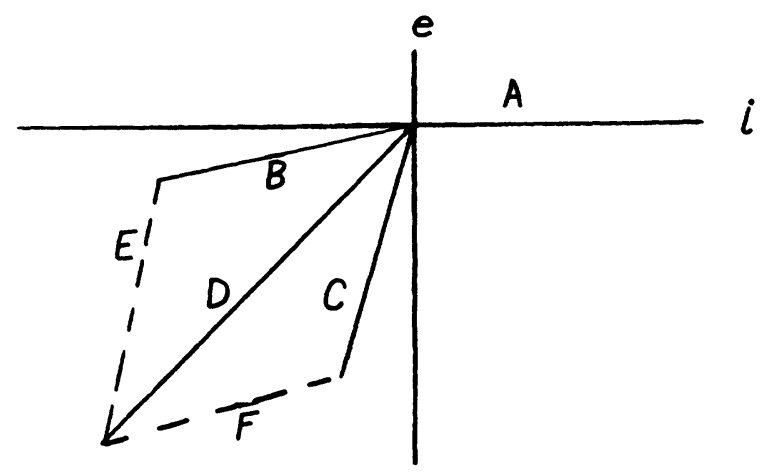

Figure 9
Item 2 suggests that a diode which has a zener characteristic would result in much higher gain if the bias is zero.

Consider Figure 9 and assume that the bias is zero. From the above combination of straight lines one can specify five combinations of curves which pass through the origin in the order of decreasing gain.

A B E

A B, A D, A C

A C F

However, there are only three values of gain associated with the five curves assuming the pump traverses the whole curve. The curve $\mathrm{ABE}$ which has the greatest gain resembles the zener diode and also to a lesser degree the SBD-524.

The important conclusion is that to decrease the loss in a passive diode mixer one must use a diode which results in a small conductance angle and has a high enough conductance in this angle to permit reasonable impedance matching assuming that the negative conductance is negligible.

\section{SUMMARY OF RESULTS}

1. It is possible to establish a lower bound on the noise figure of a mixer IF amplifier system. This lower bound is practical in the sense that one may detect measurement errors if the measured value is less than this value.

2. The gain of the passive diode mixer is dependent on the angle of conductance if the diode is "ideal". The controversial "right angle characteristic" is not desirable.

\section{REFERENCES}

1. Shih-fang Lo, "Noise in Tunnel Diode Mixer," Ph.D. Thesis, University of Minnesota, pg. 71.

2. E. W. Herold and L. Malter, "Some Aspects of the Esaki Diode Frequency Converter," Solid-State Electronics, 1961, Vol. 3, pg. 171.

3. Robert A. Pucel, "Theory of the Esaki Diode Frequency Converter," Solid-State Electronics, 1961, Vol. 3, pg. 171. 


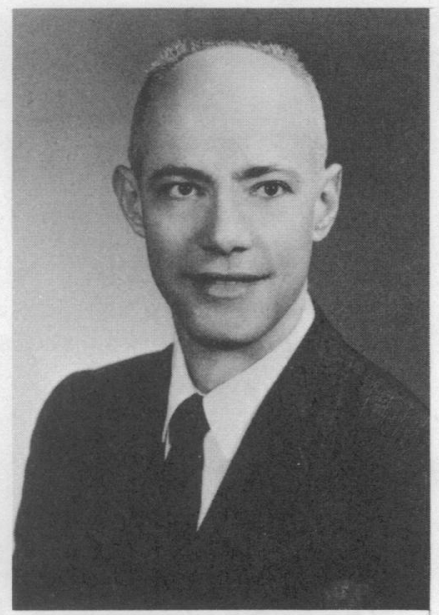

\section{BIOGRAPHY}

Grant G. Myers was born in Avoca, Iowa, on December 6, 1930. He received the B.S., M.S. and Ph.D. degrees from the University of Iowa in 1957, 1958 , and 1965, respectively. His thesis was titled, "Thermoelectric Circuits for Instrumentation and Control."

In 1958 he joined Collins Radio Company, Cedar Rapids, Iowa, where he worked on the development of $\mathrm{VHF}$ and UHF communications equipment. He also worked on a research program on frequency conversion. Presently, he is an Associate Professor of Electrical Engineering and holds a secondary appointment as Associate Professor of Physiology at the University of Nebraska, Lincoln, Nebraska.

During the summer of 1967 he was a lecturerresearcher under a Fulbright Award and NIH grant at the University of the Republic, Montevideo, Uruguay. 